\title{
COMPONENTS OF RESPIRATORY DEPRESSION AFTER NARCOTIC PREMEDICATION IN ADOLESCENTS
}

\author{
R. KNILL", J.F. CosGrove†, P. M. Olley, and H. Levison
}

NARCOTIC AGENTS are potent depressants of ventilation. ${ }^{1-\overline{5}}$ Although this effect is generally assumed to result from decreased output of the central respiratory "centres," some of the effect could be due to direct action on the ventilatory apparatus itself, by increasing respiratory impendance. For example, both morphine and meperidine can cause bronchoconstriction;" furthermore they can increase the tonic activity of abdominal and intercostal muscles..$^{7-10}$ The mechanical effects of this increase in abdominal wall tone have not been assessed after therapeutic doses of these agents, but large doses of narcotics administered intravenously produce board-like rigidity of the abdominal wall ${ }^{7-10}$ and markedly decrease total respiratory compliance." As the magnitude of this effect appears to be dose related $^{10}$, it may well be present to a lesser extent after therapeutic doses of these agents.

The purpose of this work was to determine whether the ventilatory depression associated with morphine and a meperidine-phenothiazine mixture is solely the result of impairment of the neuromuscular or force-generating mechanisms, or is in part due to increased impedance of the ventilatory pump. Even small increases in ventilatory load with narcotics probably contribute to ventilatory depression, as load compensation is poor when central neural mechanisms are pharmacologically impaired. ${ }^{11,12}$

The conventional technique for examining the effect of narcotics on ventilation is to apply rebreathing and steady-state methods before and after medication, to measure changes in minute ventilation $\left(\dot{\mathrm{V}}_{\mathrm{E}}\right)$ and tidal volume $\left(\mathrm{V}_{\mathrm{T}}\right) .^{13,14}$ However, these measurements depend on both central output and the properties of the ventilatory apparatus, ${ }^{15,16}$ without distinction between them. A newer method, formulated by Grunstein, Younes and Milic-Emili ${ }^{17}$ and modified for use in man by Whitelaw and Milic-Emili, ${ }^{18}$ provides more direct assessment of respiratorycentre output. This technique requires occlusion of the airway at functional residual capacity (FRC) for less than $200 \mathrm{msec}$; mouth pressure is measured at $100 \mathrm{msec}\left(\mathrm{P}_{\mathrm{m} 100}\right)$. Occlusion is too brief for a cortical response to interrupt the inspiratory effort, and since there is no gas flow or change in volume, the measure-

Mailing address: Dr. H. Levison, Respiratory Physiology, The Hospital for Sick Children, 555 University Avenue, Toronto, Ontario M5G 1X8.

From the Department of Paediatrics, University of Toronto, and the Research Institute, The Hospital for Sick Children, Toronto, Ontario.

"Present address: Department of Anaesthesia, University of Western Ontario, London, Ontario.

tThen Research Fellow, Canadian Cystic Fibrosis Foundation.

Supported by Grants from the Canadian Cystic Fibrosis Foundation and the Canadian Thoracic Society. 
ment is not influenced by changes in resistance or compliance of the lungs or chest wall. ${ }^{19} \mathrm{P}_{\mathrm{m} 100}$ can be measured as part of a $\mathrm{CO}_{2}$-rebreathing study; combined with the ventilatory response to $\mathrm{CO}_{2}$, it gives more detailed information about ventilation control.

In the presence of constant length and geometry of the diaphragm occlusion pressure is directly related to the isometric tension developed by the diaphragm; and, in the presence of normal phrenic nerve activity, neuromuscular and diaphragm muscle function is directly related to integrated phrenic neuronal discharge and therefore the output of the respiratory centres ${ }^{19}{ }^{19}$ Thus, the occlusion pressure $\left(\mathrm{P}_{\mathrm{m100}}\right)$ provides a convenient and simple index of the "generator" function of medullary respiratory "centres," but can be used as such only when certain neural and neuromuscular functions and diaphragm geometry remain constant. If, for instance, during an experiment there are changes in lung volume (FRC) or configuration of the chest wall, the length or curvature of the diaphragm will vary, and as a result there will be an inconstant relationship between airway occlusion pressure and diaphragm tension and, therefore, medullary drive. ${ }^{20}$ However, even with such factors varying $\mathrm{P}_{\mathrm{m} 100}$ continues to represent neuromuscular drive; that is, it is an index of the forces being generated by the neuromuscular system on the chest wall. For the purpose of this study, $P_{m 100}$ is interpreted in this manner.

\section{Materials AND METHODS}

We studied 13 patients ( 7 male, 6 female), aged 12 to 19 years (mean age, $15 \pm 2 \mathrm{yr}$ ), who were undergoing elective cardiac catheterization. They were assessed clinically by a cardiologist before study. The only criterion of selection was the patients' ability to co-operate with the investigators. Premedication, injected intramuscularly, consisted of morphine sulphate $(0.1 \mathrm{mg} / \mathrm{kg}$ body weight $)$ or $2 \mathrm{ml}$ of $\mathrm{CM}_{3} ;{ }^{21}$ each $\mathrm{ml}$ of the latter contains promethazine $\mathrm{HCl} 6.25 \mathrm{mg}$, chlorpromazine $6.25 \mathrm{mg}$, and meperidine $\mathrm{HCl} 25 \mathrm{mg}$.

Each of ten patients performed FVC expiration into a 9-litre water-filled Collins spirometer. The test of three breaths were analyzed for FVC in one sec. $\left(\mathrm{FEV}_{1.0}\right)$, and the results were expressed as a percentage of predicted normal values from standards obtained in this laboratory." Total lung capacity (TLC) and its subdivisions were measured in a variable-pressure body plethysmograph, using the technique described by DuBois, et al. ${ }^{23}$

In all 13 patients, Read's rebreathing technique ${ }^{2-}$ was used to determine the ventilatory response to carbon dioxide and $P_{m 100}$ was measured simultaneously. The subjects, comfortably supine, breathed 7 per cent $\mathrm{CO}_{2}$ in 93 per cent $\mathrm{O}_{2}$. A rapid-acting low-resistance solenoid valve was inserted into the circuit. It was activated periodically during expiration and remained closed for $200 \mathrm{msec}$ during the next inspiration. Occlusion was repeated 6 to 10 times during the four-minute rebreathing procedure. The following indices were recorded on a Beckman type $\mathrm{S} 2$ Dynograph; end-tidal carbon dioxide $\left(\mathrm{P}_{\mathrm{A}_{\mathrm{CO}}}\right)$, tidal volume $\left(\mathrm{V}_{\mathrm{T}}\right)$, gas flow, inspiratory time $\left(T_{I}\right)$ and total time $\left(T_{\text {tot }}\right)$ of each breath, and the mouth-occlusion pressure at $100 \mathrm{msec}\left(\mathrm{P}_{\mathrm{m100}}\right)$. Volumes were corrected for body temperature and pressure saturated with water (BTPS). The responses of $\dot{V}_{\mathrm{F}}, \mathrm{V}_{\mathrm{T}}$ and $\mathrm{P}_{\mathrm{m} 100}$ to increases in $\mathrm{PA}_{\mathrm{C}_{2}}$ were plotted, and the slope of each response was found by the 


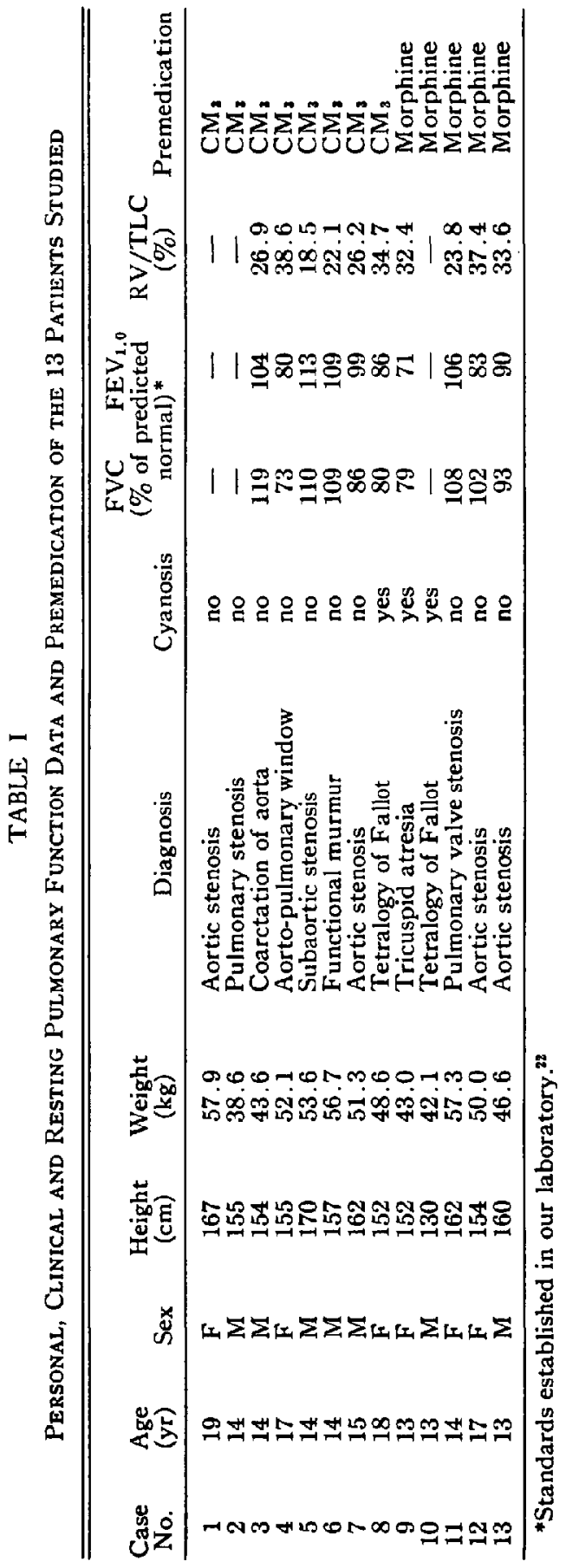



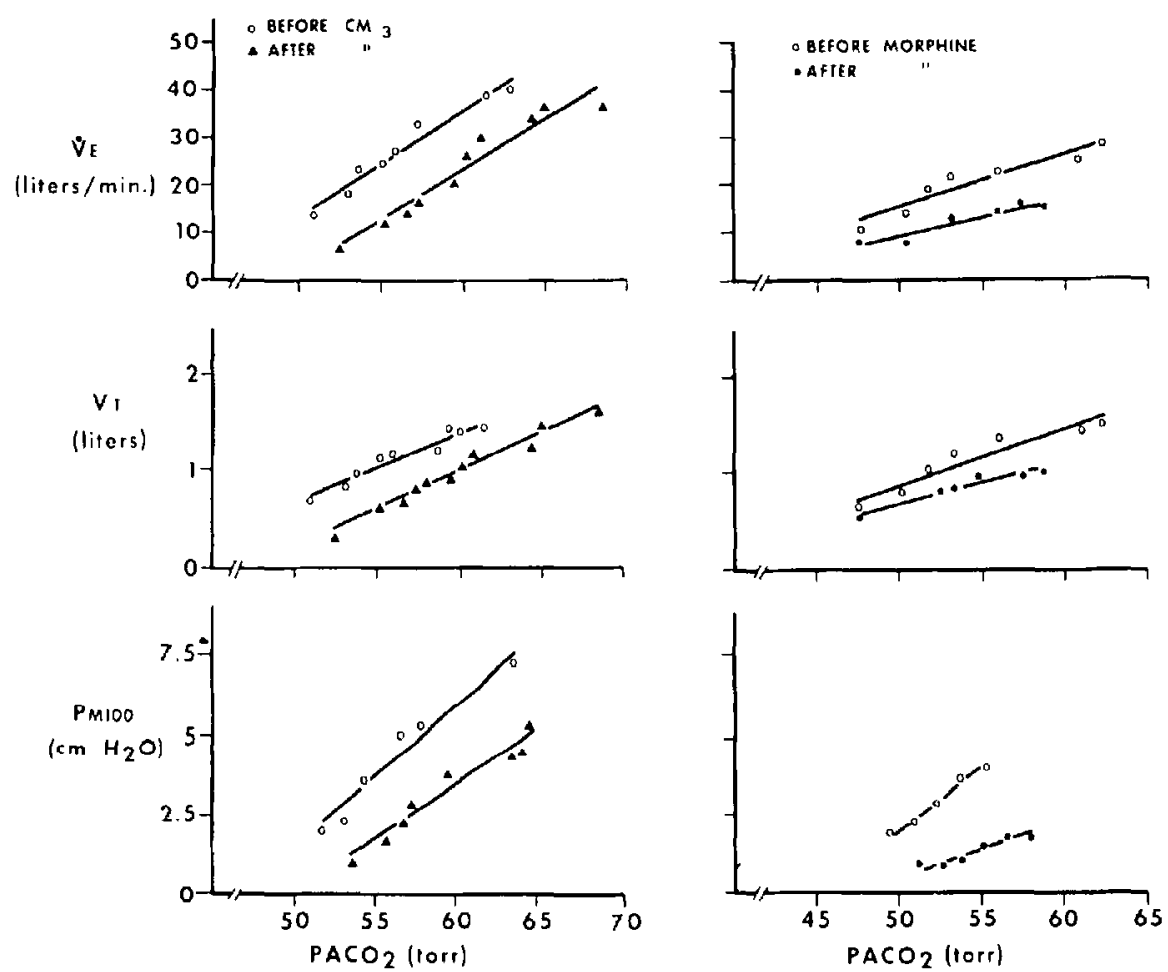

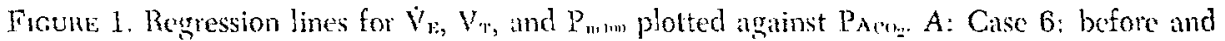
after injection of $\mathrm{CM}_{3 .} B$ : Case 11 : before and after injection of morphine.

method of least squares. To correct for variations in respiratory frequency, the ratio of $V_{\mathrm{T}}$ to inspiratory time $\left(\mathrm{V}_{\mathrm{T}} / \mathrm{T}_{\mathrm{T}}\right)$ was determined for the breath preceding an occlusion; $V_{T} / T_{1}$ was plotted against the $P_{m 100}$ value of the respective occluded breath, and the slope of this relationship also found by the method of least squares.

After completion of the first rebreathing procedure, five patients received morphine and eight were given $\mathrm{CM}_{3}$. After an interval of $47 \pm 5$ min (mean $\pm 1 \mathrm{SD}$ ) the rebreathing procedure was repeated. The patients remained awake throughout the study.

\section{Results}

In most cases, routine pulmonary function values were within normal range for age (Table I). The mean FVC was $96 \pm 16$ per cent of predicted normal, in the range 79 per cent to 119 per cent; mean $\mathrm{FEV}_{1.0}$ was $94 \pm 14$ per cent of predicted normal, in the range 71 per cent to 113 per cent, RV/TLC was in the range of 18.5 per cent to 38.6 per cent, in two cases slightly above the upper limit or normal established in our laboratory."-

The composite plot of pulmonary responses to $\mathrm{CM}_{3}$ shown in Figure $1 \mathrm{~A}$ is typical of the findings recorded in all eight patients who received this drug. Similarly, the plot shown in Figure $1 B$ is typical of the responses seen in the five patients given morphine. Both drugs depressed $\dot{V}_{\mathrm{E}}, \mathrm{V}_{\mathrm{T}}$, and $\mathrm{P}_{\mathrm{m} 100 \text {, the conventional re- }}$ sponses to $\mathrm{CO}_{2}$ ( Table II). Comparison of the ventilatory and occlusion responses 
KNILL, et al.: CO.2 $_{2}$ - RESPONSE AFTER NARCOTICS

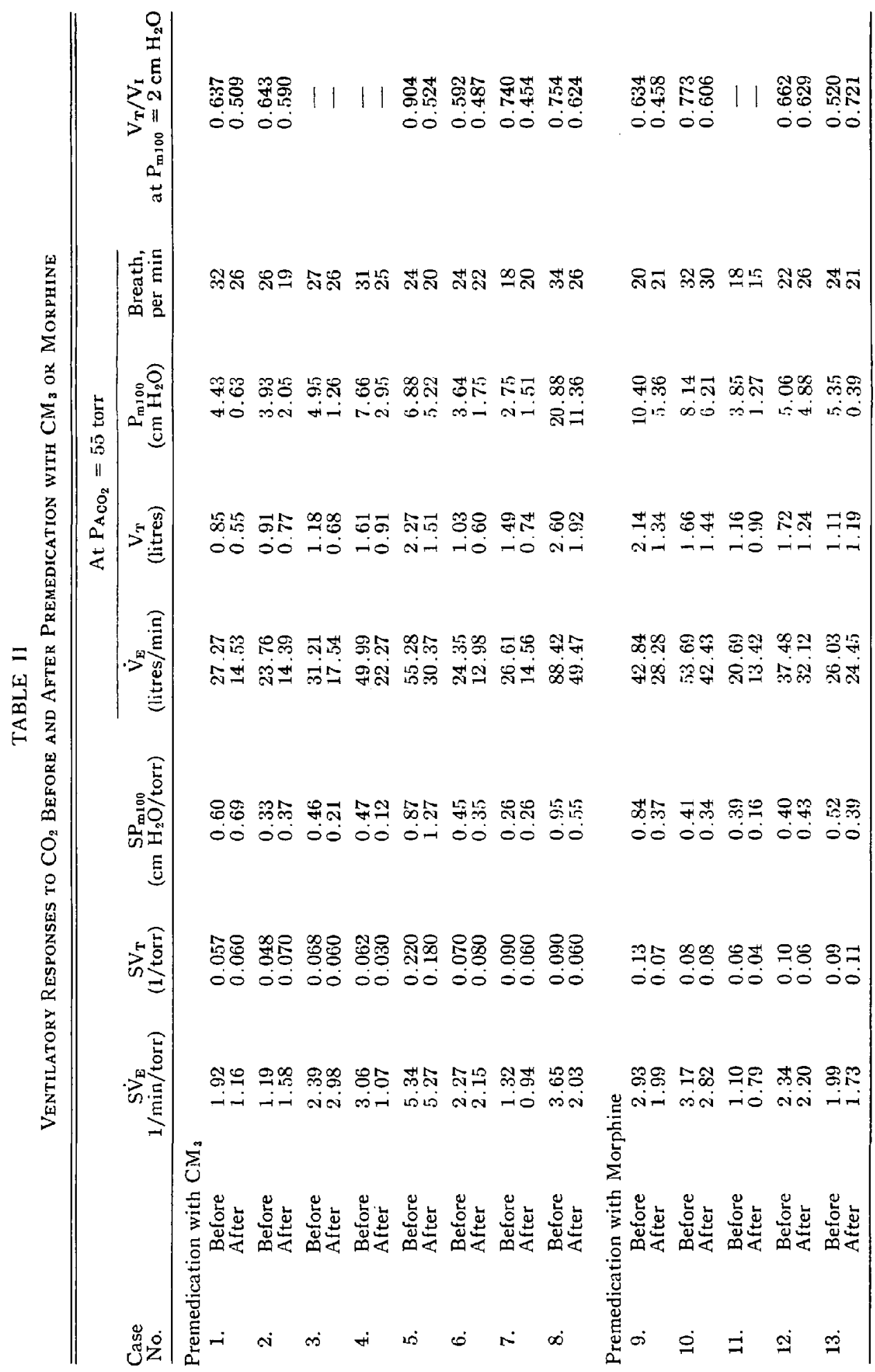




\section{$\frac{V+(L)}{T i(\sec )}$}

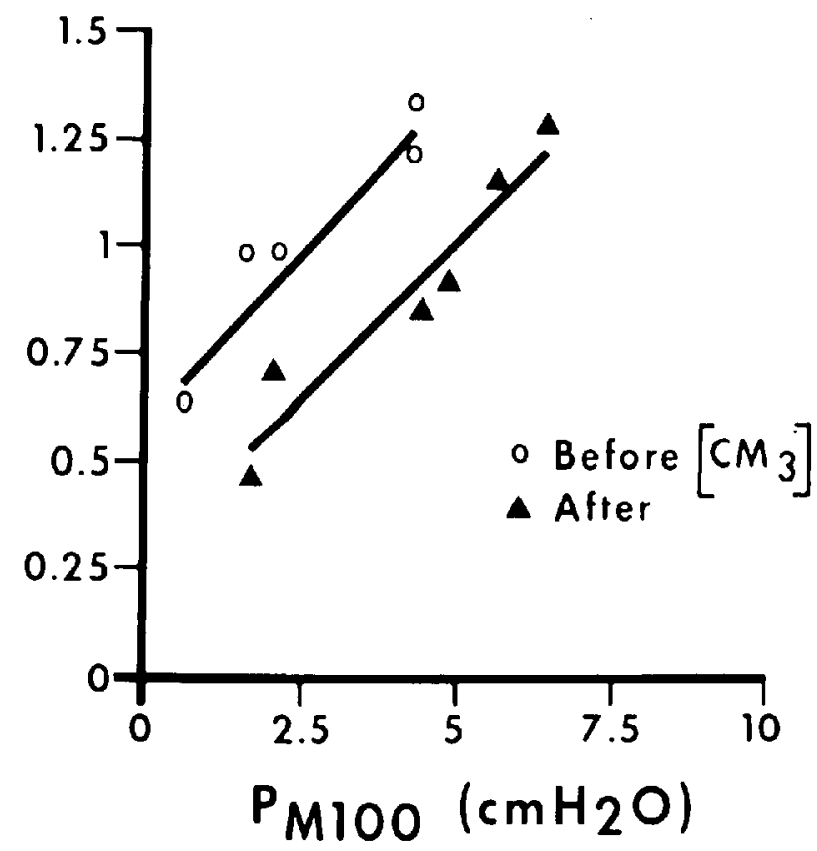

Ficure 2. Case 5: Regression line for $\mathrm{V}_{\mathrm{T}}$ of a breath preceding occlusion divided by inspiratory time plotted against $P_{111} 1 \mathrm{~m}$, before and after injection of $\mathrm{CM}_{3}$.

showed a significant decrease $(\mathrm{p}<0.05)$ in $\mathrm{V}_{\mathrm{T}} / \mathrm{T}_{\mathrm{I}}$ at a $\mathrm{P}_{\mathrm{m} 100}$ of $2 \mathrm{~cm} . \mathrm{H}_{2} \mathrm{O}$ after premedication in ten of the patients. (Three subjects did not achieve this level of drive after receiving the narcotic.)

The plot of time-corrected $\mathrm{V}_{\mathrm{T}}\left(\mathrm{V}_{\mathrm{T}} / \mathrm{T}_{\mathrm{I}}\right)$ of breaths preceding occlusions during rebreathing is $\mathrm{P}_{\mathrm{m} 100}$ of the respective occlusions showed a shift to the right after premedication with $\mathrm{CM}_{3}$ (Figure 2).

As shown in Table III, the only significant change in magnitude of the slopes after premedication was a decrease in $S \dot{V}_{\mathrm{F}}$ after morphine $(\mathrm{p}<0.05)$. At $\mathrm{PA}_{\mathrm{CO}_{2}}=$ 55 torr, there was a significant shift in all slopes after premedication with $\mathrm{CM}_{3}$, but in only $\dot{V}_{\mathrm{E}}$ and $\mathrm{P}_{\mathrm{m} 100}$ after morphine.

\section{Discussion}

The depression of ventilation by narcotics is poorly understood. In general, central nervous system depressants which reduce ventilation (e.g., barbiturates, narcotics and inhalational anaesthetics) are usually considered to affect ventilation by acting on the respiratory "centres" in the medulla. However, direct supportive evidence has not been easy to obtain. In one set of animal experiments, respiratory centres under the influence of narcotics showed decreased responsiveness to electrical stimulation. ${ }^{25}$

The main purpose of the present study was to assess the effects on ventilation of two narcotics frequently used as premedication for cardiac catheterization in chil- 


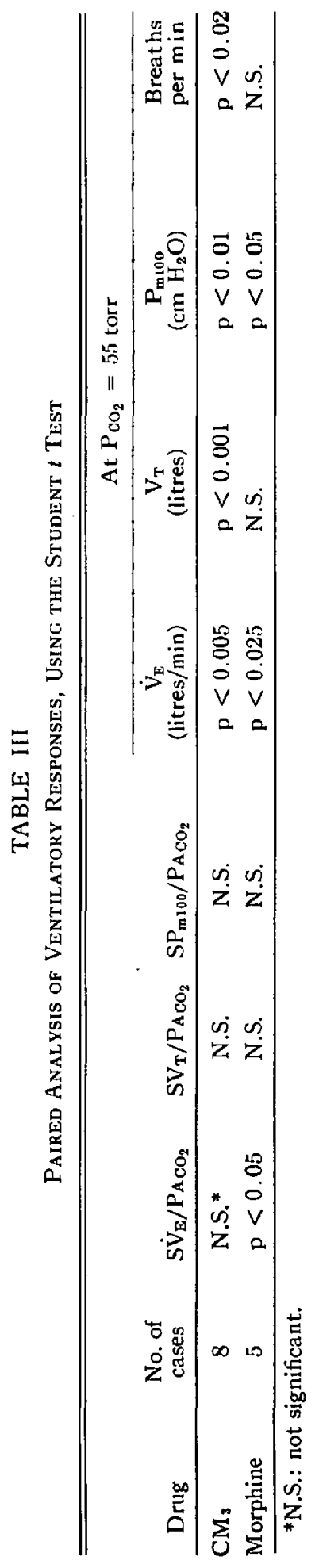


dren. In addition, it provided an opportunity to evaluate the effect of a meperidinephenothiazine mixture on ventilation. Finally, we assessed two possible modes of action of these narcotics on the respiratory system, one or both of which actions might explain their depressant effect.

Depression of the conventional response to $\mathrm{CO}_{2}$ by both morphine and $\mathrm{CM}_{3}$ was best demonstrated by a shift to the right of the $\dot{\mathrm{V}}_{\mathrm{E}} / \mathrm{PA}_{\mathrm{CO}_{2}}$ and $\cdot \mathrm{V}_{\mathrm{T}} \mathrm{PACO}_{2}$ curves (Figure 1). This shift was measured by calculating values for each curve at $\mathrm{P}_{\mathrm{A}_{\mathrm{CO}} 2}=55$ torr, a method of analysing shifts suggested by Tenney ${ }^{26}$ and Read. ${ }^{24}$ The results obtained in our patients accord with those reported after the administration of morphine and meperidine to neonates"i and adults ${ }^{+}$; similar studies have not been reported in older children. The $\mathrm{CM}_{3}$ mixture was at least as depressant as morphine alone, each narcotic being administered in approximately equipotent amount, supporting Lambertsen et al.'s conclusion ${ }^{28}$ that phenothiazine, rather than sparing narcotic depression, ${ }^{29}$ usually potentiates it.

Both drugs significantly depressed the mouth-occlusion response $\left(\mathbf{P}_{\mathrm{m100}}\right)$ to $\mathrm{CO}_{2}$. Since the $\mathrm{P}_{\mathrm{m100}}$ is a direct measurement of the neuromechanical output of the respiratory centre and there is no evidence that narcotics impair nerve or neuromuscular condition, ${ }^{30}$ we conclude that the depressant effect on neuromechanical drive reflects an action on the central nervous system. Any action which would alter the geometry of the diaphragm would also independently affect $\mathrm{P}_{\mathrm{m} 100}$, the coupling between diaphragm-tension generation and occlusion-pressure generation being highly sensitive to both the length and the radius of curvature of the diaphragm. ${ }^{20}$ We have no evidence of an effect of narcotics on diaphragm geometry, but speculate that, if present, it would consist in cephalad displacement of the diaphragm, thereby increasing the curvature of the diaphragm. Such an effect would augment $P_{\text {m100, }}$, not decrease it. ${ }^{20}$

The possibility that narcotics also affect the mechanics of ventilation, by increasing resistance or stiffness of the lungs or chest wall, was examined by comparing the ventilation achieved at varying neuromechanical drives before and after each narcotic. As the index of central drive $\left(P_{\text {m.100 }}\right)$ was taken at a fixed time of inspiration ( $100 \mathrm{msec}$ ), $\mathrm{V}_{\mathrm{T}}$ values were corrected to a fixed time unit dividing them by inspiratory time $\left(\mathrm{V}_{\mathrm{T}} / \mathrm{T}_{\mathrm{I}}\right) . \mathrm{V}_{\mathrm{T}} / \mathrm{T}_{\mathrm{I}}$ was significantly decreased $(\mathrm{p}<0.05)$ after either drug for a given $\mathrm{P}_{\mathrm{m} 100}\left(2 \mathrm{~cm} \mathrm{H} \mathrm{H}_{2} \mathrm{O}\right)$, indicating that these drugs decrease the responsiveness of the ventilatory apparatus. A decreased responsiveness of the ventilatory pump must represent a change in the compliance or resistance characteristics of either the lungs or the chest wall. The only known consistent effect of narcotics on these structures is an increase in the tonic activity of abdominal and intercostal muscles. ${ }^{-10}$ Changes in this activity might increase respiratory impedance. Increased tonic activity directly reduces chest-wall compliance, an effect which has been documented after large doses of narcotics. ${ }^{8.9}$ Alternatively, increases in intercostal and abdominal activity could disrupt the normal coupling of the motions of the diaphragm and the rib cage. This coupling usually acts to move the entire chest wall along its "relaxation characteristic," keeping the work of breathing at a minimum. ${ }^{31}$ If the tonic activity disrupted this relationship, the relative motions of the rib cage and diaphragm would change, so increasing the work of breathing and respiratory impedance. ${ }^{31}$ Studies of chest-wall motion under the influence of narcotics are needed to determine this point. 
SUMMARY

The effects of narcotics on ventilatory control were assessed in 13 adolescents and young adults. Both a narcotic and narcotic-phenothiazine significantly depressed the $\mathrm{CO}_{2}$ response curve. Using an occlusion pressure technique $\left(\mathrm{P}_{\mathrm{m100}}\right)$ to evaluate those neuromuscular processes that generate forces acting on the ventilatory pump, it was found that narcotic agents reduced neuromuscular drive. In most subjects, narcotics had an additional action that contributed to the overall ventilatory depression. Using carbon dioxide to vary neuromuscular drive before and after drug administration at constant levels of neuromuscular drive the drugs reduced tidal-volume responsiveness of the pump. We conclude that narcotics impair ventilation through a combination of two effects; first, reduced neuromuscular drive, most probably due to central depression, and second, increased impedance of the ventilatory pump, most probably due to a decrease in chest-wall compliance.

\section{RÉSUMÉ}

Les effets des analgésiques morphiniques sur le contrôle ventilatoire furent évalués chez 13 adolescents et jeunes adultes. Un analgésique de mème qu'un analgésique associé à une phénothiazine dépriment d'une façon significative la réponse au $\mathrm{CO}_{2 .}$. A l'aide d'une technique avec pression d'occlusion $\left(\mathrm{P}_{\mathrm{h}, 00}=\right.$ Pression buccale) permettant d'évaluer les mécanismes neuromusculaires générateurs des forces opérant sur la pompe ventilatoire, on a trouvé que les agents analgésiques diminuent la forc neuromusculaire. Chez la plupart des sujets, les analgésiques ont une action additionnelle qui contribue à le dépression ventilatoire globale. En variant la $\mathrm{CO}_{2}$ pour faire varier la force neuromusculaire avant et après l'administration des drogues, on a trouvé qu'à des niveaux constants de force neuromusculaire, les narcotiques diminuaient le volume courant de la pompe ventilatoire. Nous concluons que les analgésiques modifient la ventilation de deux façons, à savoir une réduction de la force neuromusculaire probablement par dépression centrale et par une augmentation de l'impédance de la pompe ventilatoire, vraisemblablement due à une chute de la compliance thoracique.

\section{REFERENCES}

1. Kneugen, H., Edoy; N.B., \& Summalt, M. The phamacology of the opium alkaloids. USPHS, Pulbic Health Rep., Suppl. 165, 1941.

2. Edpy, N.B., Haluach, H., \& Braenden, O.]. Synthetic substances with morphine-like effect. Clinical experience: potency, side-effects, addiction liability. Bull. WHO, 17: 569 (1957).

3. Reynolds, $A$. \& Randall, L.O. Morphine and allied drugs. University of Toronto Press, Toronto, Ontario (1957).

4. ЕскекноFғ, J.E. \& Oесн, S.R. The effects of narcotics and antagonists upon respiration and circulation in man. A review. Clin. Pharmacol. Ther. 1:483 (1960).

5. Hiccins, H.L. \& MEANs, J.H. The effect of certain drugs on the respiration and gaseous metabolism in nomal human subjects. J. Pharmacol. Exp. Ther. 7: 1 (1915).

6. Mitchell, H.S. \& DEJoNG, J.D. The effect of morphine on bronchial muscle. J. Allergy, 25: $302(1954)$.

7. Hashlon, W.K. \& Cullex, S.C. Supplementation of nitrous oxide anaesthesia with opiates and a new opiate antagonist. Anesthesiology 16:22 (1955). 
8. Sokoll, M.D., Hoyt, J.L., \& Gergrs, S.D. Studies in muscle rigidity, nitrous oxide, and narcotic analyesic agents. Anesth. Analg. 51: 16 (1972).

9. Fheund, F.G., Mahtin, W.E., Wong, K.C., \& Honnbein, T.F. Abdominal-muscle rigidity induced by morphine and nitrous oxide. Anesthesiology $38: 358$ (1973).

10. Grell, F.L., Koons, R.A., \& Denson, J.S. Fentanyl in anesthesia: a report of 500 cases. Anesth. Analg. 49: 523 (1970).

11. Mahgahie, C.E., Iscoe, S., Pengelly, L.D., Couture, J., Don, H., \& Milic-EMili, J. Immediate ventilatory response to elastic loads and positive pressure in man. Resp. Physio. 18: 347 (1973).

12. Freedian, S. \& Caxipeell, E.J.M. The ability of normal subjects to tolerate added inspiratory loads. Respir. Physiol. 10: 213 (1970).

13. ECKENHOFF, J.E., HeLRICH, M., \& HeGE, M.J.D. A method for studying respiratory functions in awake or anesthetized patients. Anesthesiology 17:66 (1956).

14. LaMinertsen, C.J. Effects of drugs and hormones on the respiratory response to carbon dioxide. In: Handbook of Physiology, Section 3 (Respiration), vol. 1: W.O. Fenn and H. Hahn (eds.) Washington, D.C. American Physiological Society, p. 545 ( 1964 ).

15. Cherniak, R.M. \& Sxidal, D.P. The effect of obstruction to breathing on the ventilatory response to $\mathrm{CO}_{2}$. J. Clin. Invest. 35: 1286 (1956).

16. KellogG, R.H. Central chemical regulation of respiration. In: Handbook of Physiology, Section 3 (Respiration) vol. 1: W.O. Fenn and H. Rahn (eds.) Washington, D.C., American Physiological Society, p. 507 ( 1964).

17. Ghunstein, M.M., Younes, M., \& Milic-Emili, J. Controls of tidal volume and respiratory frequency in anesthetized cats. J. Appl. Physiol. 35: 463 (1973).

18. Whitelaw, W.A. \& Milic-EMiLI, J. A new method of evaluating respiratory centre output. Physiologist, 16: 486 (1973).

19. Whitelaw, W.A., Derenne, J.P., \& Milic-Emili, J. Occlusion pressure as a measure of respiratory center output in conscious man. Respir. Physiol. 23: 181 (1975).

20. Grassino, A. Influence of chest wall configuration on the static and dynamic characteristics of the contracting diaphragm. In: Pengelly, L.D., Rebuck, A.S., \& Campbell, E.J.M. (eds.). Loaded Breathing, Toronto, Longmans, Canada p. 64 (1974).

21. SMITH, C., Rowe, R.D., \& V VAD, P. Sedation of children for cardiac catheterization with an ataractic mixture. Can. Anaesth. Soc. J., 5: 35 (1958).

22. Wenc, T.R. \& Levison, H. Standards of pulmonary function in children. Am. Rev. Respir. Dis. 99: 879 (1969).

23. DuBors, A.B., Botelho, S.Y., Bedel, G.N., Marshale, R., \& Comroe, J.H., Jr. A rapid plethysmographic method for measuring thoracic gas volume: a comparison with a nitrogen washout method for measuring functional residual capacity in normal subjects. J. Clin. Invest. 35: 322 (1956).

24. READ, D.J.C. A clinical method for assessing the ventilatory response to carbon dioxide. Aust. Ann. Med. 16: 20 (1967).

25. Pentiah, P., Reilly, F., \& Borison, H.L. Interactions of morphine sulfate and sodium salicylate on respiration in cats. J. Pharmacol. Exp. Ther. 110: 154 (1966).

26. Tenney, S.M. The interpretation of respiratory drug effects in man. Anesthesiology 17: $82(1956)$.

27. WaY, W.L., CostLeY, E.C., \& WaY, E.L. Respiratory sensitivity of the newborn infant to mepheridine and morphine. Clin. Pharmacol. Ther. 6: 454 (1965).

28. Lambertsen, C.J., Wendel, H., \& Longenhacen, J.B. The separate and combined respiratory effects of chloropromazine and meperidine in normal men controlled at $46 \mathrm{~mm}$. Hg alveolar pCO... J. Pharmacol. Exp. Ther. 131: 381 (1961).

29. ReckLEss, D. Action of chlorpromazine and promethazine. Br. Med. J. 1: 1035 (1954).

30. Goodman, L.S. \& Gilman, A. The Pharmacological basis of therapeutics, vol. 4, ed. New York, Macmillan, p. 241 (1970).

31. Mead, J. Mechanics of the chest wall. In: Pengelly, L.D., Rebuck, A.S., \& Campbell, E.J.M. (eds.). Loaded Breathing. Toronto, Longmans, Canada, p. 35 ( 1974). 